\title{
The effects of school violence on education in Malawi
}

Stephanie Psaki

Population Council

Barbara Mensch

Population Council

Erica Soler-Hampejsek

Follow this and additional works at: https://knowledgecommons.popcouncil.org/departments_sbsr-pgy

Part of the Demography, Population, and Ecology Commons, Domestic and Intimate Partner Violence Commons, Educational Sociology Commons, Family, Life Course, and Society Commons, and the International Public Health Commons

How does access to this work benefit you? Let us know!

\section{Recommended Citation}

Psaki, Stephanie, Barbara Mensch, and Erica Soler-Hampejsek. 2017. "The effects of school violence on education in Malawi," Brief. New York: Population Council. 


\section{THE EFFECTS OF SCHOOL VIOLENCE ON EDUCATION IN MALAWI}

\section{STEPHANIE R. PSAKI, BARBARA S. MENSCH, ERICA SOLER-HAMPEJSEK}

In response to a global policy effort to increase school enrollment, in 1994 Malawi became one of the first low-income countries to eliminate primary school fees. Since then, Malawi has achieved nearly universal primary enrollment. ${ }^{1}$ Enrolling young Malawians in school has not, however, translated into keeping them in school. Fewer than $6 \%$ of 15-19-year-olds have completed primary school.2 With rapid increases in enrollment has come deteriorating school quality; ${ }^{3}$ many young people who complete primary school lack basic literacy skills. ${ }^{4}$ In addition, an estimated 250 million young people experience violence in school annually, raising the question of whether school violence may contribute to the high dropout rates and low levels of learning in Malawi and similar settings.

This policy brief describes the nature and consequences of school violence in rural Malawi. We find that violence at school is a common experience for both girls and boys. However, we find little evidence that school violence disrupts schooling as expected, with the exception of sexual violence experienced at school by boys. Violence at home is also common, and may disrupt schooling for both girls and boys. Our findings emphasize the need for an integrated view of gender, education, and violence in order to implement effective programs and policies to curb school-related gender-based violence (SRGBV) and improve education outcomes for young people in Malawi and around the world.

\section{FULL STUDY GOALS, METHODOLOGY, AND FINDINGS:}

Psaki, S.R., Mensch, B.S., Soler-Hampejsek, E. 2017. "Associations between violence in school and at home and education outcomes in rural Malawi: A longitudinal analysis." Comparative Education Review 61(2): 354-390.

\section{Statistical Snapshot of Malawi}

- Malawi is one of the poorest countries in the world, ranked 170 out of 188 countries on the UNDP's Human Development Index. ${ }^{5}$

- Yet in 1994, Malawi was one of the first low-income countries to eliminate primary school fees. ${ }^{6}$

- Elimination of school fees led to nearuniversal primary school enrollment, but few young people complete primary school.

- School resources deteriorated between 2000 and 2007: student-teacher ratios increased by more than $25 \%$, and the number of pupils per classroom increased by nearly $10 \% .^{8}$

- Nearly half of adult women married before turning 18, compared to less than $10 \%$ of men. Of 15-19-year-old women, nearly a third have begun childbearing. ${ }^{9}$ 
The Malawi Schooling and Adolescent Study (MSAS)

MSAS followed the same 2,646

adolescents, male and female,

for seven years (2007 to 2013)

over six rounds of data collection.

This school violence study uses

data on the approximately 1,800

participants who were attending

school at baseline.

- At baseline, participants

were:

- Ages 14-17

- Living in rural southern

Malawi (Balaka and

Machinga districts)

- Both in and out of school

- Survey included questions on

household characteristics,

schooling history and

experiences, employment,

health, marriage, sexual

behavior, and pregnancy

- Literacy and numeracy assessments were conducted in each round

\section{Grounding advocacy in evidence}

An estimated 250 million young people globally experience school violence every year. ${ }^{10}$ In 2014, a coalition of more than 30 governments, development organizations, civil society activists, and research institutions, including the Population Council, formed the Global Working Group to End SRGBV. In part due to the group's advocacy efforts, the need to prevent and address SRGBV was included in the Sustainable Development Goals (4a). The Global Working Group is committed to generating and disseminating evidence to inform more effective policies and programs to prevent SRGBV and address its consequences. ${ }^{11}$

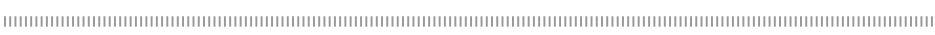

UNGEI and UNESCO define school-related gender-

based violence (SRGBV) as "acts or threats of sexual, physical, or psychological violence occurring in and around schools, perpetrated as a result of gender norms and stereotypes, and enforced by unequal power dynamics." SRGBV is commonly categorized as psychological, physical, and sexual, although there is important overlap between these areas. ${ }^{12}$

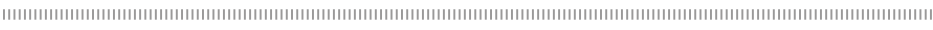

Policymakers are currently focused on identifying the reasons for high levels of primary school dropout in many low-income countries. Yet few studies have rigorously examined the ways that school and domestic violence affect education, despite the pervasive assumption that these experiences disrupt learning.

Understanding the impact of widespread violence is crucial, both to protect young people, and to avoid reversing the tremendous progress made globally in increasing school enrollment. Assumptions about the causes of primary school dropout, and low levels of learning, feed directly into the development of policies and programs. Beliefs about these complex issues must be rooted in evidence. 


\section{Methodology}

We analyzed data on nearly 1,800 adolescent girls and boys ( 869 girls, 884 boys) in rural, southern Malawi.

All students were enrolled in school at the start of the study. The goal was to understand how widespread SRGBV is, and whether it disrupts young people's education. Unlike other studies on this topic, data for MSAS were collected over seven years, from 2007 to 2013 , allowing the researchers to determine whether experiencing violence in a certain year was linked with poorer education performance in the subsequent year. Another unique element of this study is that we administered simple literacy and numeracy tests each year, rather than relying on students' subjective assessments of their own school performance.

We investigated the following forms of violence:

- Sexual harassment, sexual violence, or physical violence in the current school year; and

- Recent (in the last month) or lifetime experience of domestic violence.

We examined whether these forms of violence contributed to poorer school performance related to:

- Absenteeism in the current school year;

- Literacy and numeracy scores in the subsequent school year; and

- School dropout by the subsequent school year.

The study incorporated information on other factors potentially linked both to the experience of violence and education outcomes, including: ethnic group, household wealth, and early schooling experiences such as grade repetition and late entry to school.

\section{Glossary of terms}

In order to measure specific types of SRGBV, students were asked wehether they had had any of the following experiences in school or on their way to school in the current school year:

- Had sexual comments made to them (sexual harassment)

- Been punched, slapped, or whipped (physical violence)

- Been touched or pinched on the breasts, buttocks, or genitalia (sexual violence)

We also asked all study participants about whether they had experienced domestic violence ever in their lives, and in the month preceding the survey. Specifically, we asked whether anyone in their household had pushed, shaken, or thrown something at them, punched, slapped, or whipped them, or kicked or dragged them.

“Absenteeism" measures how often young people miss school on days when school is in session. We measure absenteeism by asking students: 1) whether they have ever missed a day of school this year; 2 ) whether they attend school regularly; 3) whether they attended school the last day school was in session; and 4) how many days of school they attended in the previous week.

“Learning" measures whether young people gain basic skills in school. We measure learning in two ways, based on: 1) a score on a Chichewa reading comprehension assessment, involving reading a short passage aloud and answering 6 questions about it; and 2) a score on a numeracy assessment, including 12 questions on ordering numbers, addition, subtraction, multiplication, division, and word problems.

"School dropout" measures when students left school, permanently in the case of our study, for any reason. In each round, young people were asked whether they were currently attending school or whether they had attended the most recent school term if it had ended. 


\section{Key findings}

1 Violence at school is common. Girls and boys are equally likely to experience school violence.

2 School violence does not disrupt schooling-with the exception of sexual violence experienced at school by boys.

3 Violence at home is also common. Domestic violence may disrupt schooling for both girls and boys, but in different ways: girls are more likely to drop out, while boys are more likely to be absent.

\section{KEY FINDING 1}

Violence at school is common. Girls and boys are equally likely to experience school violence. Overall, $51 \%$ of girls and $53 \%$ of boys ages 14-17 had experienced some type of SRGBV in the current school year at baseline. About one-third of students (girls and boys) had experienced physical violence, and $15 \%$ had experienced sexual violence, in school in the current year. The assumption that school violence disproportionately affects girls is not supported by this study. For young people (girls and boys) who remained in school, the risk of experiencing physical or sexual violence in school decreased as they got older, but the risk of sexual harassment increased.
Girls and boys are equally likely to experience school violence

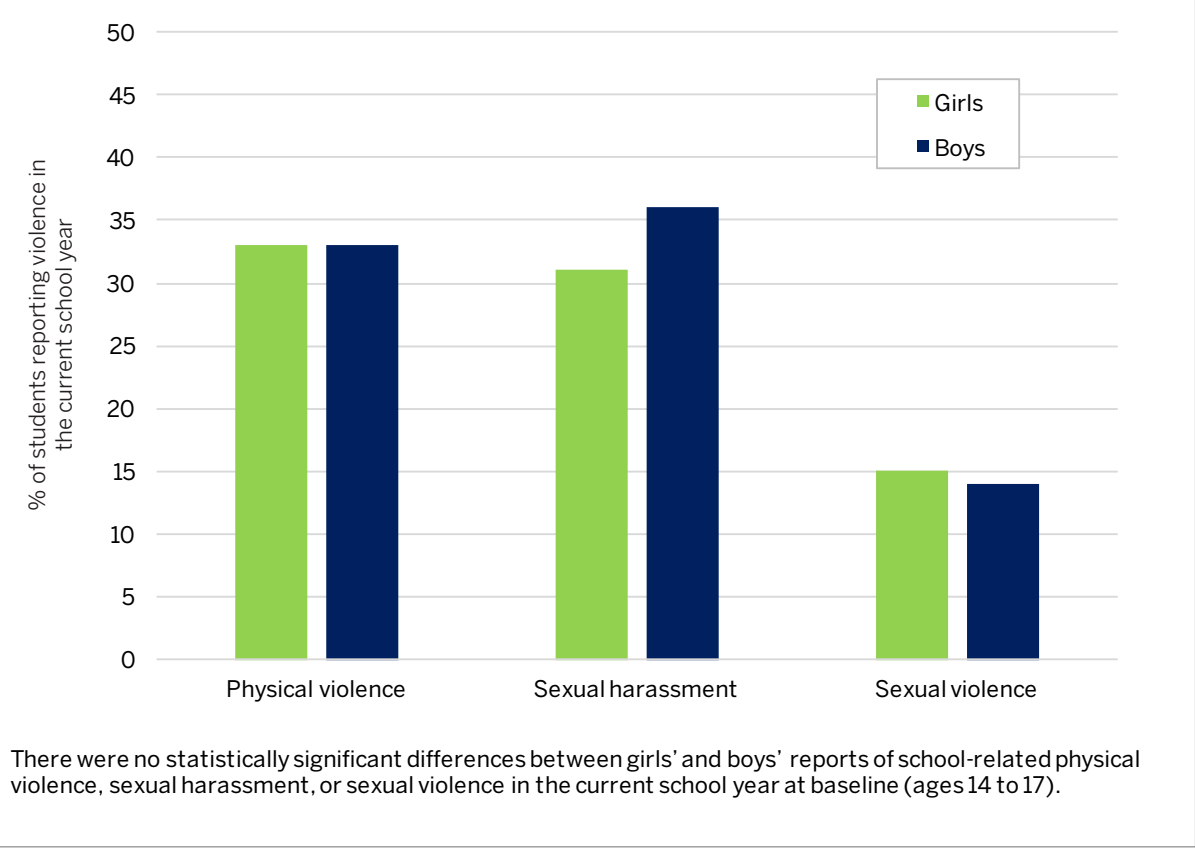




\section{KEY FINDING 2A}

School violence does not disrupt schooling-with the exception of sexual violence experienced at school by boys. Both school violence and absenteeism were equally common for girls and boys. However, school violence was mostly unrelated to absenteeism, calling into question the prevailing assumption that violence causes girls to miss school more than boys. Physical violence in school was also unrelated to nearly all measures of school performance in the current and subsequent school years for both girls and boys.

\section{KEY FINDING 2B}

Sexual violence in school was linked to worse education outcomes for boys. Girls and boys ages $14-17$ years were equally likely to report experiencing sexual violence in school (14\% of boys, $15 \%$ of girls). Four years later (ages 17-20), although the risk had decreased overall, girls (11\%) were more likely than boys (6\%) to experience sexual violence in school. But boys who reported experiencing sexual violence in the current school year were more than $50 \%$ more likely than peers who did not experience sexual violence to be absent from school in the current year; $40 \%$ less likely to perform well on literacy tests; and 50\% more likely to drop out of school by the subsequent year.
School violence does not cause school dropout, with the exception of sexual violence for boys
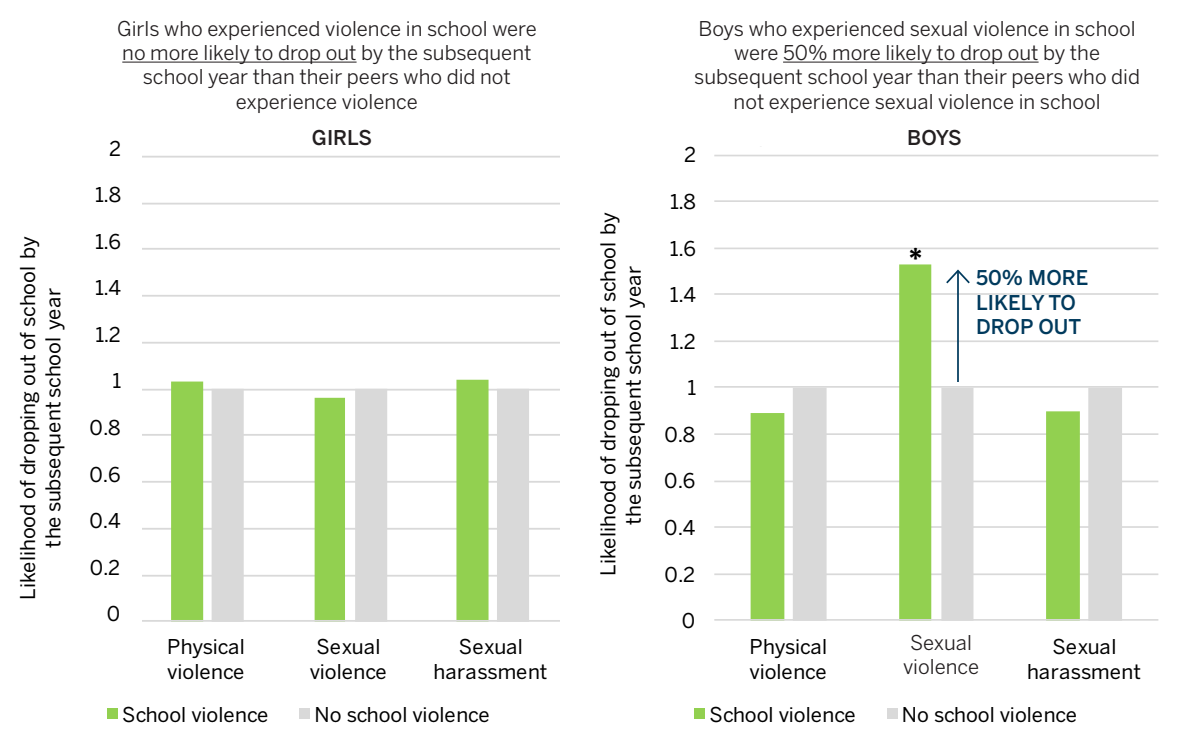

The numbers shown represent the likelihood of dropping out of school by the subsequent school year. A value greater than 1 for those who experienced school violence means they were more likely to drop out of school than their peers who did not experience violence. Statistically significant differences are indicated by an asterisk.

School violence does not lead to poorer learning outcomes, with the exception of sexual violence for boys
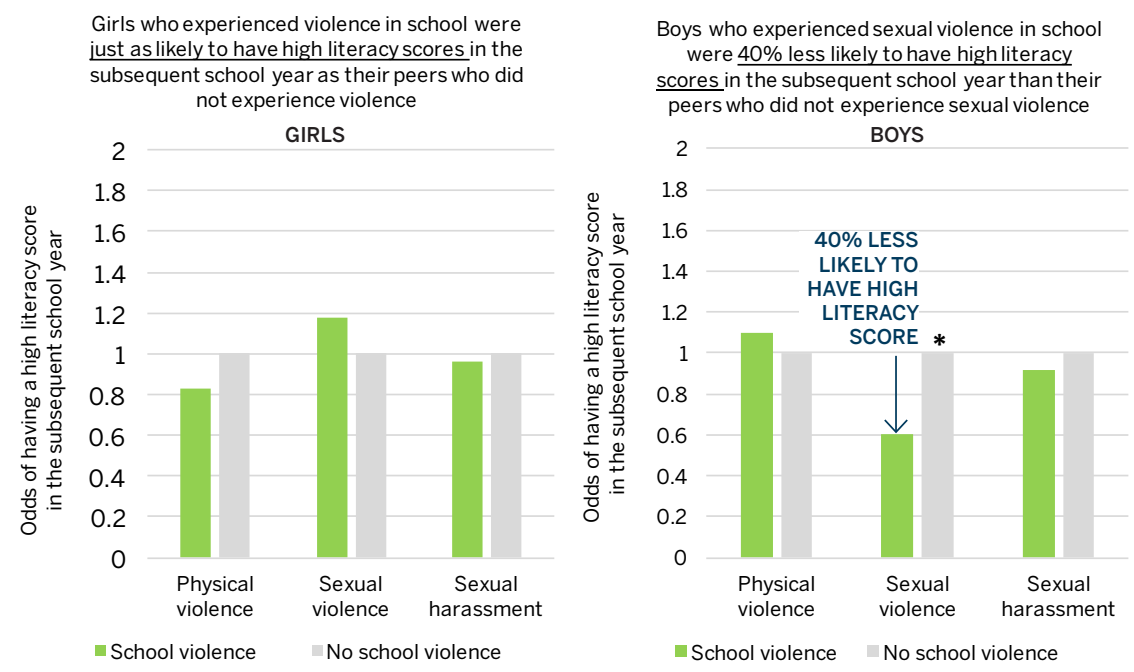

The numbers shown represent the odds of having a high literacy score in the subsequent school year. A value less than 1 for those who experienced school violence means they were less likely to have a high literacy score than their peers who did not experience violence. Statistically significant differences are indicated by an asterisk. 


\section{KEY FINDING 3}

Violence at home is also common. Domestic violence disrupts schooling for both girls and boys, but in different ways: girls are more likely to drop out, while boys are more likely to be absent. One out of four boys and girls (ages 14-17) had experienced physical violence at home in the previous month. Of those attending school at ages $14-17,72 \%$ of girls versus $45 \%$ of boys had dropped out by ages $18-21$. Girls who had experienced domestic violence were $20 \%$ more likely than their peers who had not experienced it to drop out of school by the subsequent year. Boys who had experienced domestic violence were nearly 70\% more likely than their peers to be absent from school in the same year, but not more likely to drop out. The risk of experiencing domestic violence in the last month decreased for both girls and boys as they got older. But at most ages, girls were more likely than boys to report that they had ever experienced domestic violence (44\% of girls versus $39 \%$ of boys by ages 14-17).
Domestic violence disrupts schooling for both girls and boys, but in different ways
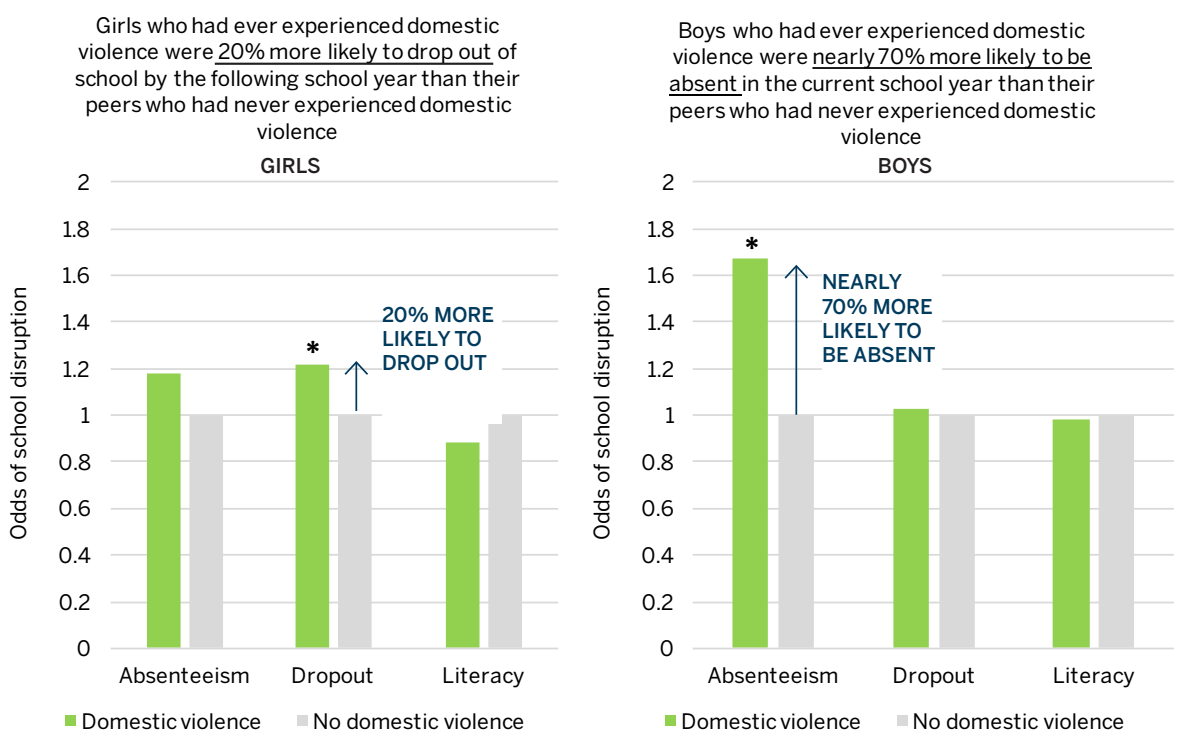

The numbers shown represent the odds of dropping out of school by the subsequent school year (left) or being absent from school in the current school year (right). A value greater than 1 for those who experienced school violence means they were more likely to experience one of those schooling disruptions than their peers who did not experience violence. Statistically significant differences are indicated by asterisks. 


\section{Policy recommendations}

A combination of factors in young people's environments likely contribute to the high levels of primary school dropout and poor learning outcomes in Malawi. Policies must reflect this complexity in order to be effective at improving education outcomes.

Our findings point to several policy recommendations:

- As enrollment increases, ensure sufficient resources are available to improve or maintain school quality, in addition to testing and scaling up innovative approaches to preventing SRGBV. Among other support, schools should have: well-trained female and male teachers, sufficient facilities and materials, curriculum linked to life and workforce skills, appropriate class sizes, and safe environments.

- Address barriers outside of school that affect young people's success, such as poverty and unplanned pregnancies. Addressing school violence alone, while important, may not have a substantial impact on education outcomes without addressing the numerous other barriers to receiving a quality education.

- Ensure SRGBV programs work with girls and boys, and address gender inequality more broadly. Just as school violence reflects the environment in which it occurs, so must programs address the many gender-inequitable messages that young people receive, such as expectations that girls will be compliant and boys will be aggressive or violent. ${ }^{13}$
- Address household and community norms around violence, and engage parents and other community leaders to transform attitudes about the acceptability of violence. For students experiencing domestic violence, skipping school or dropping out may not be an effective strategy for avoiding violence. Parents may be aware of, and even endorse, the use of some types of violence, like corporal punishment for the purposes of discipline. At the same time, parents and community members may be powerful forces in holding schools accountable for keeping their children safe.

- Implement SRGBV programs tailored to the type of violence, the perpetrator, and the setting. Whereas teachers were the most common perpetrators of physical violence in school in our study, reflecting the frequent use of corporal punishment, ${ }^{14}$ peers were the most common perpetrators of sexual violence. The causes of, and therefore interventions needed to prevent, these types of violence may be different. 


\section{Conclusions}

Alongside success in getting young people into school, evidence of widespread school violence is mounting in numerous low-income countries. As more children enter school, the potential to transform unequal gender norms and ensure young people have the skills necessary for productive and healthy lives is unprecedented. And yet, beyond the immediate impacts, witnessing and experiencing violence during this critical period may lead to a higher risk of experiencing and perpetrating violence in adulthood. As enrollment continues to increase globally, policymakers must ensure that schools provide safe, high-quality learning environments for all children.

The findings from this study contribute to an evolving understanding of the effects of cultures of violence on young people. Effective policies to address violence in schools must also address violence at home and in communities. These experiences cannot be disentangled when trying to understand the impacts on young people.

More research is needed on the impact of SRGBV on education outcomes, as well as physical and mental health; effective approaches to preventing SRGBV and supporting young people who have experienced it; and preventing violence in young people's lives more broadly, including in their homes.

\section{Notes}

1,2 National Statistical Office (NSO) [Malawi] and ICF. 2017. Malawi Demographic and Health Survey 201516. Zomba, Malawi, and Rockville, Maryland, USA: NSO and ICF.

3 Grant, Monica J. 2015. "The demographic promise of expanded female education: Trends in the age at first birth in Malawi." Population and Development Review 41(3): 409-438.

4 See, for example, results from the Southern and Eastern Africa Consortium for Monitoring Educational Quality (SACMEQ) III in Malawi, available at: www.sacmeq.org.

5 UNDP Human Development Report 2016. Available at: http://hdr.undp.org/sites/default/files/2016_human_ development_report.pdf.

6 Grant 2015.

$7 \quad \mathrm{NSO}$ and ICF 2017.

8 SACMEQ III.

$9 \quad$ NSO and ICF 2017.

10, 11 UNGEI, UNESCO, Global Working Group to End School-Related Gender-Based Violence. Brochure. Available at: http://www.ungei.org/srgbv/files/ SRGBV_WGBrochure_Print(1).pdf.

12 UNGEI (UN Girls' Education Initiative) and UNESCO. 2015. "School-Related, Gender-Based Violence Is Preventing the Achievement of Quality Education for All." Policy Paper 17. New York: UNGEI.

13 Leach, F. and S. Humphreys. 2007. "Gender violence in schools: Taking the 'Girls-as-victims' discourse forward." Gender and Development 15(1): 51-65.

14 Although corporal punishment in government schools is prohibited in the Malawian Constitution, the 2012 Education Act failed to address this issue. Laws around corporal punishment at home are less clear. More information is available at: http://www. endcorporalpunishment.org/assets/pdfs/statesreports/Malawi.pdf.

\footnotetext{
Research reported in this article was supported by grants from the Eunice Kennedy Shriver National Institute of Child Health and Human Development (R01HD047764 and R01HD062155), the William and Flora Hewlett, John D. and Catherine T. MacArthur, Spencer, and Ford Foundations, and the Economic and Social Research Council Secondary Data Analysis Initiative (ES/L013967/1). The content is solely the responsibility of the authors and does not necessarily represent the official views of the funding institutions. This policy brief benefited from input from Rachel Friedman, Lisa Polen, and Thoai Ngo.
}

(c) 2017 The Population Council, Inc. 